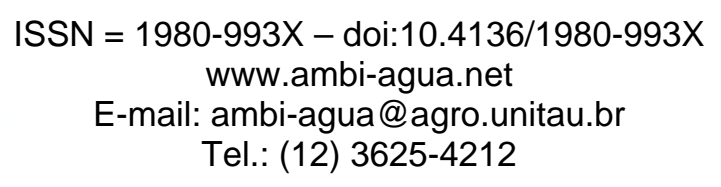

\title{
Impactos causados pelas mudanças climáticas nos processos erosivos de uma bacia hidrográfica: Simulação de cenários
}

\author{
(http://dx.doi.org/10.4136/ambi-agua.200) \\ Thatiana Aparecida Lelis ${ }^{1}$; Maria Lúcia Calijuri²; Aníbal Santiago da Fonseca ${ }^{3}$; \\ Dario Cardoso de Lima ${ }^{4}$;
Doutora em Engenharia Civil; Universidade Federal de Viçosa - UFV; e-mail: thatianalelis@yahoo.com.br, Universidade Federal de Viçosa - UFV; e-mail:calijuri@ufv.br, e-mail:anibalsantiago@gmail.com,
Universidade Federal de Viçosa - UFV; e-mail:declima@ufv.br, \\ Mestrando em Engenharia Civil, Universidade Federal de Viçosa - UFV;
}

\section{RESUMO}

As mudanças climáticas previstas para ocorrem nos próximos anos devem ter sérios reflexos nos processos erosivos, tendo como fatores principais a intensificação dos picos de chuva e o aumento da temperatura, em todo o planeta. Vários estudos têm sido realizados para estimar os cenários de mudanças climáticas e neste enfoque, foi realizado este trabalho na bacia do ribeirão São Bartolomeu, na Zona da Mata de Minas Gerais. A partir do cenário A1B, proposto pelo Painel Intergovernamental de Mudanças Climáticas (IPCC), que faz uma projeção para o aquecimento médio global da superfície da Terra, foi estimada a produção de sedimentos e de escoamento superficial, utilizando-se o SWAT (Soil and Water Assessment Tool). Os cenários simulados, segundo as mudanças climáticas previstas para acontecerem nos próximos 90 anos, são bastante alarmantes, com taxas de perda de solo e escoamento muito superiores às atualmente encontradas nas culturas analisadas, podendo chegar até a três vezes mais em uma situação crítica de aumento do volume precipitado e maior ocorrência de picos de precipitação.

Palavras-chave: perda de solo; escoamento superficial; erosão.

\section{Impacts of climate change on erosion of a watershed: Simulation of scenarios}

\section{ABSTRACT}

Climate change set to occur in the coming years should have severe effects on erosion process, as factors leading to intensification of the peaks of rainfall and increasing temperature on the entire planet. Several studies have been performed to estimate climate change scenarios. This work was implemented in the Sao Bartolomeu's watershed, in Minas Gerais' Forest Zone. From the A1B scenario proposed by the Intergovernmental Panel on Climate Change (IPCC), that set a projection for the global mean warming of Earth's surface, sediment production and runoff were estimated using SWAT (Soil and Water Assessment Tool). The simulated scenarios for projected climate changes that could happen in the next 90 years are quite alarming, with soil loss and runoff rates production much higher than those currently found in the cultures analyzed, reaching up to three times more in a critical increase in the rainfall volume and higher peaks of precipitation.

Keywords: soil loss; runoff; erosion. 


\section{INTRODUÇÃO}

O uso inadequado dos solos agrícolas vem causando a perda gradual da sua capacidade produtiva e a contaminação dos recursos hídricos por sedimentos e poluentes de origem difusa. De acordo com Amorim (2000), o processo erosivo constitui-se na principal causa de degradação dos solos trazendo, em consequência, prejuízos ao setor agrícola e ao meio ambiente, com reflexos econômicos e sociais. Tendo como agravante os efeitos das mudanças ambientais globais, uma das incertezas críticas para os próximos anos refere-se às alterações que poderão ocorrer nos processos erosivos. Amore et al. (2004) assumem tal preocupação, afirmando que os problemas relacionados com a erosão do solo podem se acentuar bastante no futuro, em muitas partes do mundo, em decorrência das mudanças climáticas e consequente intensificação dos processos relacionados ao ciclo hidrológico.

$\mathrm{O}$ planeta passa por um período de aumento da concentração de $\mathrm{CO}_{2}$ que condiciona grandes mudanças climáticas, resultantes de uma complexa inter-relação entre ações humanas e causas naturais. Nas últimas décadas, os fenômenos naturais se intensificaram - ondas de calor, furacões, enchentes e aumento do nível do mar - havendo maior ocorrência de eventos extremos de precipitação e temperatura, muitas vezes causados por ações antrópicas, trazendo alertas para o futuro da população e sustentabilidade do planeta. Segundo relatórios da Convenção Quadro da ONU sobre Mudança do Clima (UNFCCC, 1992), as mudanças climáticas globais trarão uma extensa lista de impactos ambientais e socioeconômicos em áreas tão díspares, quanto abastecimento de água, agricultura, segurança alimentar, saúde, biodiversidade e zonas costeiras. Mudanças no padrão de chuvas trarão, em conjunto com o derretimento das geleiras, deficiências no suprimento de água, ocorrência de enchentes, além de potencializar as perdas de solo, consequência direta do agravamento dos processos erosivos.

Dessa forma, os processos erosivos representam um problema, não somente pela perda de solo como meio de suporte às atividades agrícolas, promovendo o declínio da fertilidade dos solos, mas também por trazerem consequências negativas relacionadas ao assoreamento e contaminação dos cursos d'água, lagos e represas em nível local ou até mesmo em grandes áreas, impactando diretamente a população em relação à geração de energia elétrica, irrigação e abastecimento de água (Clarke e Silva Dias, 2002; Santos et al., 2010). É importante destacar que o fator mudança climática assume um peso bem maior quando associado à perda do solo em regiões tropicais, onde as variações de temperatura e precipitação controlam, de forma mais intensa, a magnitude dos processos erosivos (Amore et al., 2004; IPCC, 2007; Machado et al., 2008; Xavier, 2009).

Segundo o IPCC (2007), o aquecimento do sistema climático já não é mais um equívoco. As mudanças por ele induzidas têm provocado o aumento da frequência e da intensidade de eventos de extremos climáticos (furacões, tempestades tropicais, inundações, ondas de calor, seca ou deslizamentos de terra) e afetado a duração dos períodos de estiagem e enchente, além de outras consequências como a redução da produção das atividades agrícolas, a perda de qualidade das culturas e alterações significativas da disponibilidade hídrica em muitas regiões (Marengo, 2004; Streck e Alberto, 2006; Novo e Ferreira, 2007; IPCC, 2007).

Mudanças nas temperaturas extremas têm sido evidenciadas em todos os lugares nos últimos 50 anos, sendo assim mais frequentes as ondas de calor e frio. A frequência das precipitações mais fortes também têm aumentado sobre a maioria das regiões continentais, bem como secas mais longas e mais intensas, principalmente nas regiões tropicais e subtropicais (IPCC, 2007).

Caso os cenários de aquecimento global se confirmem, espera-se, além de um aumento dos eventos extremos de precipitação, tanto em termos de volume quanto de intensidade de precipitação, que o ciclo hidrológico tenha uma grande variabilidade, em várias escalas de tempo (sazonal, anual, decadal, etc). Esses fatores provocam consequências diretas na 
evapotranspiração e nos fluxos de escoamento, que são o principal agente responsável pela perda de solo, conforme analisam Mermut et al. (1997), Amorim (2004), Brandão et al. (2007), Carvalho (2008) e Lopes (2008), cujos picos podem ser maiores que os historicamente observados (Mohammed, 2009). Nesse sentido, as alterações nas taxas de evapotranspiração e no tempo de concentração do escoamento superficial das bacias podem explicar o impacto nas produções de sedimentos e escoamento superficial.

Ademais, há de se levar em conta, também, que os efeitos dos eventos climáticos extremos tornam-se mais graves na medida em que existe maior vulnerabilidade associada ao uso e à ocupação do solo, tanto nas áreas rurais quanto nas urbanas (Nunes e Pacheco, 2004; Marengo, 2004; Streck e Alberto, 2006; Novo e Ferreira, 2007; IPCC, 2007; Xavier, 2009).

Para o planejamento adequado do desenvolvimento de uma região, informação é um elemento-chave para qualquer medida de controle e tomada de decisão. Por isso, a Convenção Quadro da ONU sobre Mudança do Clima (UNFCCC, 1992) ressalta a importância de estabelecer sistemas de monitoramento que analisem tanto parâmetros climáticos (temperaturas, chuvas e frequência de eventos extremos), quanto outros dados relacionados, como disponibilidade de recursos hídricos e produtividade agrícola, que afetem a dinâmica dos processos erosivos e o desenvolvimento sustentável de uma área.

Entretanto, as alterações na produção de água e sedimentos em uma bacia hidrográfica, em função das mudanças no clima mundial, nem sempre podem ser quantificadas devido à falta de monitoramento das vazões líquida e sólida. Mas, atualmente, é possível simular os impactos advindos dessas alterações climáticas através da construção de cenários, utilizando como ferramenta básica modelos matemáticos associados a Sistemas de Informações Geográficas, que facilitam a manipulação e interpretação dos dados. Dentre esses modelos, destaca-se o SWAT, ferramenta principal deste trabalho.

O SWAT foi desenvolvido para verificar os efeitos resultantes das modificações no uso do solo sobre o escoamento superficial e subterrâneo, bem como na produção de sedimentos, e tem sido estudado e difundido mundialmente, com resultados satisfatórios, conforme pode ser visto no trabalho de Lelis e Calijuri (2010).

Em razão da gravidade do problema relacionado ao aquecimento global, a análise integrada para quantificação dos impactos das mudanças climáticas nos vários aspectos ambientais e sociais tem despertado atenção e discussões ao redor do planeta. Alguns autores realizaram estudos a respeito da simulação de cenários de alteração climática e seus impactos no ambiente, utilizando o SWAT, dentre os quais podem ser citados Nunes e Pacheco (2004), Gassman et al. (2007) e Gouvea (2008).

Mas, em geral, essas avaliações têm se concentrado em escala global e as alterações climáticas em lugares específicos ou em pequenas bacias ainda permanecem sem estudos na maior parte do mundo (IPCC, 2007; Mohammed, 2009). Por isso, identificar os impactos das mudanças climáticas em nível de bacia hidrográfica é tão importante, pois possibilita definir os graus de vulnerabilidade dos recursos hídricos e planejar ações adequadas de adaptação local, além de definir os futuros riscos para o desenvolvimento de projetos ambientais em uma dada região.

Sendo assim, a partir dos estudos realizados na bacia do ribeirão São Bartolomeu (Lelis e Calijuri, 2010; Lelis, 2011), os quais identificaram os fatores que mais influenciam no processo erosivo e determinaram as perdas de solo e água ocorridas na região no período de 2006 a 2008, o objetivo deste trabalho foi avaliar os impactos na produção de sedimentos e escoamento superficial provocados por possíveis mudanças climáticas na bacia, seguindo as previsões do Relatório Especial sobre Previsões de Emissões (SRES) do IPCC (2007), a partir do SWAT. Vale a pena destacar que este não foi um trabalho de previsão de cenários de mudanças climáticas e para tanto não foi utilizado nenhum simulador climático para prever as variações na temperatura e precipitação. 


\section{MATERIAIS E MÉTODOS}

\section{1. Área de estudo}

O presente trabalho tem foco na sub-bacia hidrográfica do ribeirão São Bartolomeu, localizada entre as coordenadas $20^{\circ} 44^{\prime} \mathrm{S}$ e $42^{\circ} 53^{\prime} \mathrm{O}$, no município de Viçosa, Zona da Mata de Minas Gerais, Brasil. A bacia ocupa uma área de 5.422 ha, representando cerca de $18 \%$ da área do município, e faz parte da bacia do rio Piranga, a qual é uma sub-bacia do rio Doce, conforme apresentado na Figura 1.

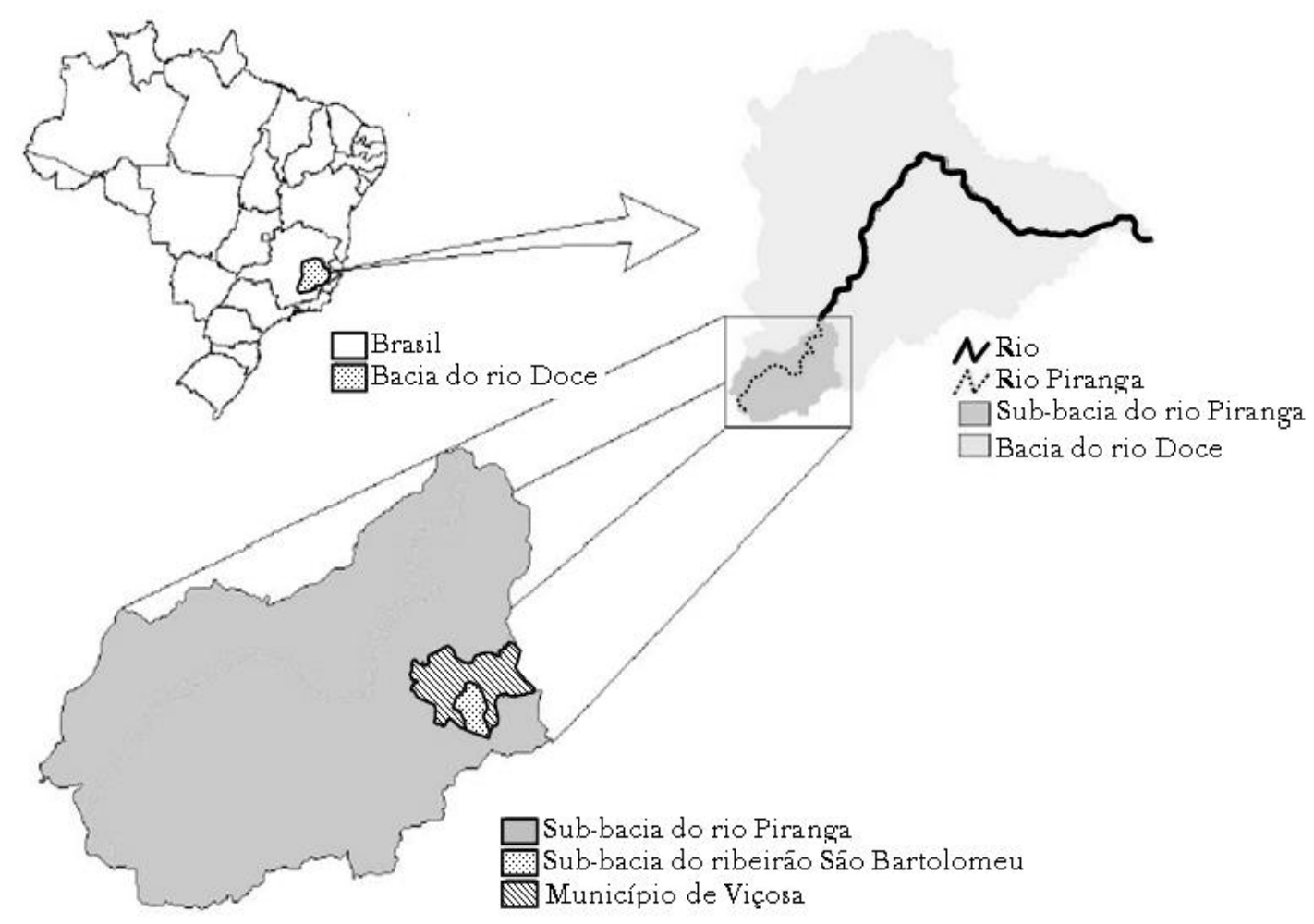

Figura 1. Localização da sub-bacia do ribeirão São Bartolomeu na bacia do rio Doce.

De acordo com a classificação de Köppen, o clima é do tipo $C w b$, ou seja, tropical de altitude com verões frescos e chuvosos (EMBRAPA, 1982).

Os dados climatológicos diários relativos à temperatura, precipitação, umidade relativa do ar, velocidade do vento foram obtidos junto ao Instituto Nacional de Meteorologia (INMET), a partir de um histórico de dados de estações meteorológicas de Viçosa e outras estações próximas, conforme se apresenta na Tabela 1: 
LELIS, T. A.; CALIJURI, M. L.; FONSECA, A. S. da; LIMA, D. C. de. Impactos causados pelas mudanças climáticas nos processos erosivos de uma bacia hidrográfica: Simulação de cenários. Ambi-Agua, Taubaté, v. 6, n. 2, p. 282-294, 2011. (doi:10.4136/ambi-agua.200)

Tabela 1. Estações meteorológicas - Dados de precipitação e temperatura.

\begin{tabular}{|c|c|c|c|c|c|}
\hline \multirow{2}{*}{ Estação } & \multirow{2}{*}{ Elev (m) } & \multicolumn{2}{|c|}{ Localização } & \multicolumn{2}{|c|}{ Dados } \\
\hline & & Lat. & Lon. & Início & Fim \\
\hline Barbacena & 1126 & $21^{\circ} 15^{\prime} \mathrm{S}$ & $43^{\circ} 46^{\prime} \mathrm{W}$ & $01 / 01 / 90$ & $31 / 12 / 09$ \\
\hline Juiz de Fora & 940 & $21^{\circ} 46^{\prime} \mathrm{S}$ & $43^{\circ} 21^{\prime} \mathrm{W}$ & $01 / 01 / 91$ & $31 / 12 / 09$ \\
\hline São João del Rei & 991 & $21^{\circ} 18^{\prime} \mathrm{S}$ & $44^{\circ} 16^{\prime} \mathrm{W}$ & $01 / 01 / 91$ & 01/06/06 \\
\hline Viçosa & 690 & $20^{\circ} 45^{\prime} \mathrm{S}$ & $42^{\circ} 51^{\prime} \mathrm{W}$ & 01/09/90 & $31 / 12 / 09$ \\
\hline
\end{tabular}

Fonte: INMET.

\subsection{O SWAT}

O SWAT é um programa de domínio público desenvolvido para estudar e predizer o escoamento, produção de sedimentos, carga de poluentes e qualidade da água em bacias hidrográficas.

A modelagem ambiental no SWAT é realizada com uma grande quantidade de componentes hidrológicos em uma bacia e, juntamente com os componentes de clima, ciclo hidrológico, produção de sedimentos e cobertura do solo, simula os processos de escoamento e produção de sedimentos (Reungsang et al., 2009).

Especificamente em relação aos dados climatológicos, as estatísticas obtidas a partir das séries de dados das estações apresentadas na Tabela 1, são adicionadas ao SWAT na interface apresentada na Figura 2. Nesta mesma interface é que são alterados os dados a fim de se realizarem simulações de cenários de mudanças climáticas:

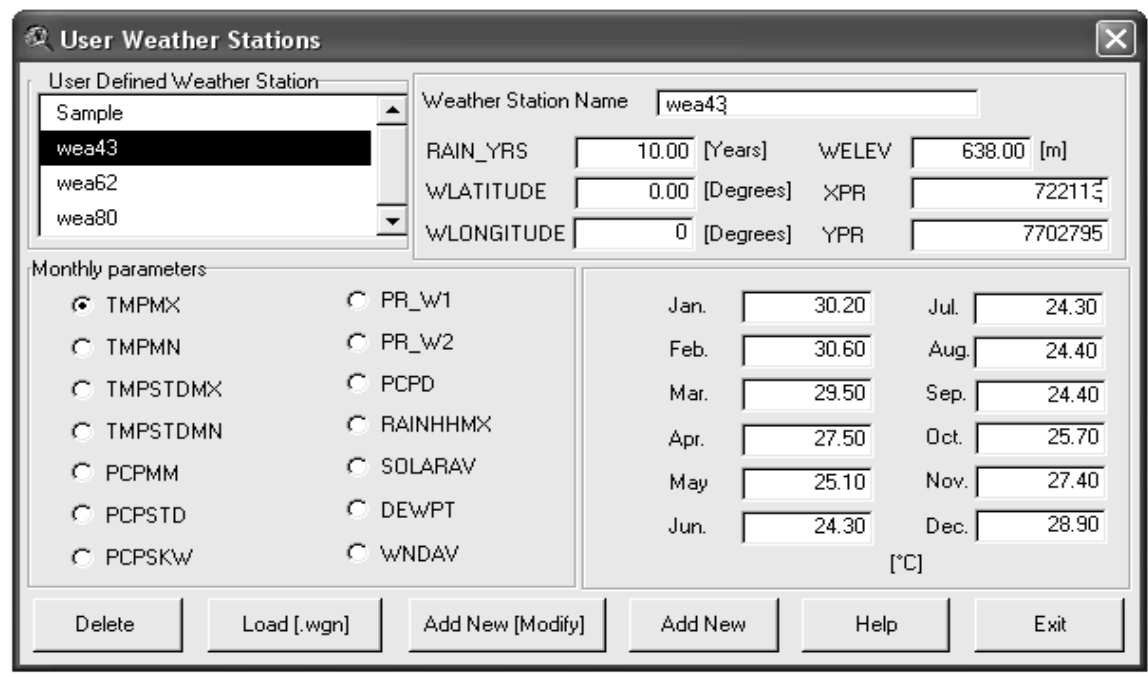

Figura 2. Entrada dos dados climatológicos no SWAT.

\subsection{Simulação de cenários de mudanças climáticas}

Tendo em vista que o foco deste trabalho não é a previsão de cenários de mudanças climáticas, e sim de estudos de impactos possíveis de ocorrer no futuro em função das alterações na temperatura e precipitação no planeta, foi utilizada a expectativa de um dos órgãos mais gabaritados em previsões climáticas em escala mundial.

Assim, no contexto das mudanças climáticas previstas para o século XXI, o IPCC (2007), no Relatório Especial sobre Previsões de Emissões (SRES), fez uma projeção para o aquecimento médio global da superfície da Terra, de acordo com os cenários apresentados na Tabela 2, obtidos a partir de tendências estimadas de emissão de $\mathrm{CO}_{2}$. 
Tabela 2. Projeção do aquecimento médio global da superfície no final do século XXI.

\begin{tabular}{|c|c|c|}
\hline \multirow[t]{2}{*}{ Caso } & \multicolumn{2}{|c|}{$\begin{array}{c}\text { Mudança de temperatura } \\
\left({ }^{\circ} \mathrm{C} \text { em } 2090-2099 \text { relativa a } 1980-\right. \\
1999)\end{array}$} \\
\hline & Melhor estimativa & Faixa provável \\
\hline $\begin{array}{c}\text { Concentrações constantes do ano } \\
2000\end{array}$ & 0,6 & $0,3-0,9$ \\
\hline Cenário B1 & 1,8 & $1,1-2,9$ \\
\hline Cenário A1T & 2,4 & $1,4-3,8$ \\
\hline Cenário B2 & 2,4 & $1,4-3,8$ \\
\hline Cenário A1B & 2,8 & $1,7-4,4$ \\
\hline Cenário A2 & 3,4 & $2,0-5,4$ \\
\hline Cenário A1F1 & 4,0 & $2,4-6,4$ \\
\hline
\end{tabular}

Fonte: IPCC (2007).

Esses cenários representam diversas condições climáticas, conforme descritos a seguir:

A1: este cenário descreve um mundo futuro com rápido crescimento econômico, população global que atinge seu pico na metade do século e, então passa a declinar, e introdução de tecnologias novas e mais eficientes. Os temas fundamentais são convergência entre regiões, construção de capacidade e crescente interação social e cultural, com redução substancial em diferenças regionais e em renda per capita. Este cenário se subdivide em três grupos que descrevem direções alternativas de mudança tecnológica no sistema de energia, com ênfase no uso intensivo de fontes fósseis (A1FI), fontes de energia não fóssil (A1T) ou um equilíbrio entre todas as fontes (A1B).

A2: este cenário descreve um mundo muito heterogêneo, em que o fundamento é a autoconfiança e a manutenção de identidades locais. O crescimento da população é contínuo. O desenvolvimento econômico é essencialmente orientado para a região e se tem crescimento econômico per capita e desenvolvimento tecnológico mais fragmentados e lentos do que em outros cenários.

B1: este cenário descreve um mundo convergente com a mesma população que atinge seu pico na metade do século e, então passa a declinar, como no cenário A1, mas com rápidas mudanças nas estruturas econômicas, orientado por uma economia de informação e serviços, com redução nos materiais e tecnologias eficientes e limpas. A ênfase está em soluções globais para a sustentabilidade econômica, social e ambiental, incluindo maior equidade.

B2: este cenário descreve um mundo no qual a ênfase está sobre soluções locais para sustentabilidade econômica, social e ambiental. É um mundo com população global continuamente crescente, em taxa mais baixa do que no cenário A2, com níveis intermediários de desenvolvimento econômico e progresso tecnológico menos acelerado e mais diversificado do que nos modelos B1 e A1. Enquanto o cenário também é orientado em direção à proteção ambiental e igualdade social, também foca nos níveis local e regional.

Mesmo genéricas, essas projeções atendem bem ao objetivo da pesquisa, que é interpretar a variação da produção de sedimentos e escoamento superficial provocada por possíveis mudanças climáticas na bacia.

No SWAT é possível tanto simular o efeito do acréscimo de $\mathrm{CO}_{2}$, quanto mudanças na temperatura e precipitação causadas por acréscimos assumidos dessa concentração na atmosfera (Jha et al., 2006).

Sendo assim, a partir do modelo SWAT calibrado para a bacia do ribeirão São Bartolomeu (Lelis, 2011), foram realizadas simulações de cenários considerando as condições climáticas do cenário A1B, definido pelo IPCC (2007), que é um cenário intermediário de 
emissões de $\mathrm{CO}_{2}$ na atmosfera, como visto na Figura 3. Segundo as previsões, considerandose as temperaturas atuais como referência, foi considerado que em 2099 elas poderão sofrer uma elevação de $1,7^{\circ} \mathrm{C}$ até $4,4^{\circ} \mathrm{C}$, conforme apresentado na Tabela 2 e visualizado na Figura 3.

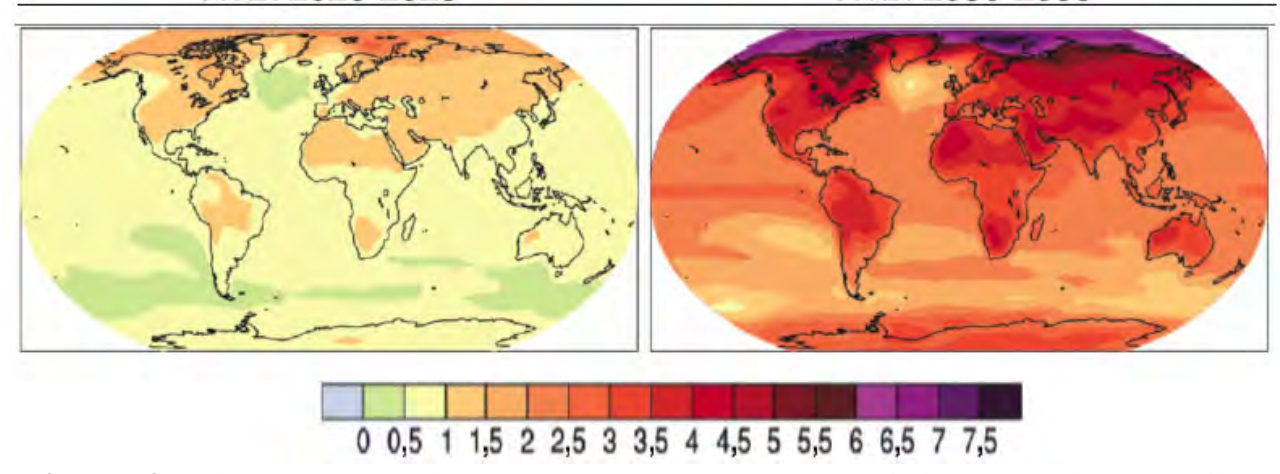

Figura 3. Alterações previstas na temperatura de superfície para o início e final do século 21 em relação ao período 1980-1999.

Fonte: IPCC, 2007.

Já em relação à precipitação, segundo as previsões e considerando-se as precipitações atuais como referência, foi considerado que em 2099 poderá haver uma variação entre $-5 \%$ a $5 \%$ no período do verão e entre $-20 \%$ a $-10 \%$ no inverno, para a região de Viçosa, como ilustrado na Figura 4. Os valores previstos são médias multimodelo baseadas no cenário A1B para dezembro-fevereiro (esquerda) e junho-agosto (direita). As áreas brancas representam intervalos nos quais menos de $66 \%$ dos modelos coincidem com o sinal da mudança e as hachuradas representam locais em que mais de $90 \%$ dos modelos coincidem com o sinal da mudança (IPCC, 2007).

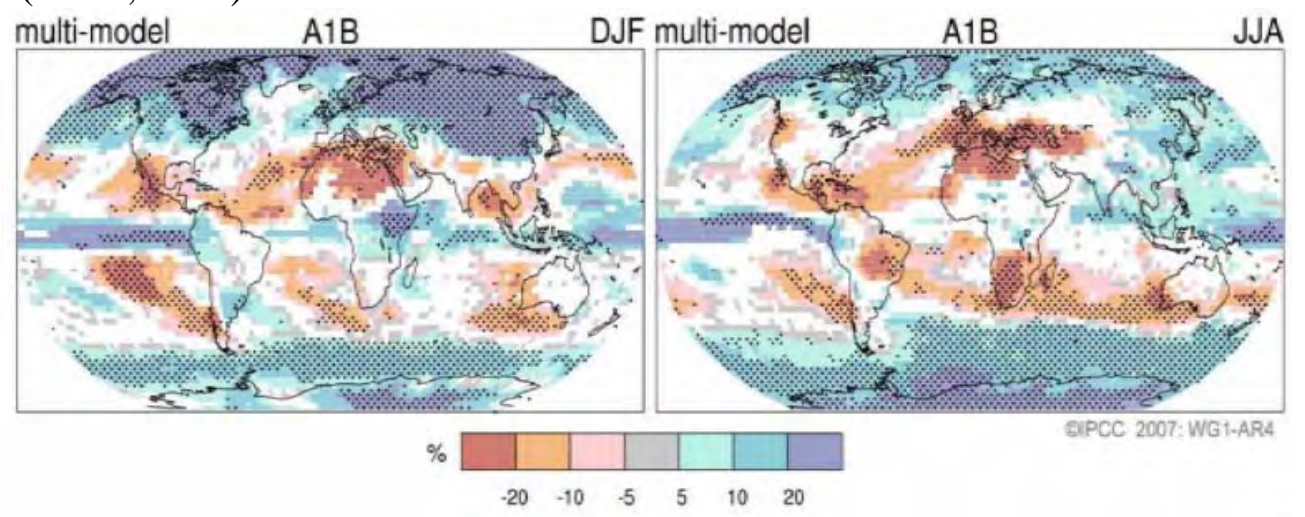

Figura 4. Alterações relativas da precipitação para o período 2029-2099, em relação a 1980- 1999.

Fonte: IPCC, 2007.

Os cenários simulados foram construídos a partir de mudanças nos volumes precipitados e na temperatura média diária, conforme os valores e porcentagens da Tabela 3, seguindo o SRES A1B do IPCC, isto é, para todos os dias dos períodos de dados apresentados na Tabela 1, para cada localidade, foi realizada a variação proposta pela Tabela 3. A entrada, no SWAT, desses novos dados para simulação de cenários foi realizada pela interface apresentada pela Figura 2. Para a simulação destes cenários, o SWAT pode ser bastante eficaz, pois contabiliza o escoamento superficial em termos diários, o que permite ter em conta, mesmo que de uma forma simplificada, o efeito dos eventos extremos de precipitação na erosão. 
LELIS, T. A.; CALIJURI, M. L.; FONSECA, A. S. da; LIMA, D. C. de. Impactos causados pelas mudanças climáticas nos processos erosivos de uma bacia hidrográfica: Simulação de cenários. Ambi-Agua, Taubaté, v. 6, n. 2, p. 282-294, 2011. (doi:10.4136/ambi-agua.200)

Tabela 3. Cenários de alteração climática simulados pelo SWAT.

\begin{tabular}{|c|c|c|c|c|c|c|c|c|c|c|c|c|c|}
\hline \multicolumn{2}{|c|}{ Cenário proposto } & $\mathbf{J}$ & $\mathbf{F}$ & $\mathbf{M}$ & $\mathbf{A}$ & $\mathbf{M}$ & $\mathbf{J}$ & $\mathbf{J}$ & A & $\mathbf{S}$ & $\mathbf{O}$ & $\mathbf{N}$ & $\mathbf{D}$ \\
\hline \multirow{2}{*}{1} & $\operatorname{Temp}\left({ }^{\circ} \mathrm{C}\right)$ & 2,8 & 2,8 & 2,8 & 2,8 & 2,8 & 2,8 & 2,8 & 2,8 & 2,8 & 2,8 & 2,8 & 2,8 \\
\hline & Precip (\%) & -5 & -5 & -5 & -20 & -20 & -20 & -20 & -20 & -20 & -5 & -5 & -5 \\
\hline \multirow{2}{*}{2} & Temp $\left({ }^{\circ} \mathrm{C}\right)$ & 2,8 & 2,8 & 2,8 & 2,8 & 2,8 & 2,8 & 2,8 & 2,8 & 2,8 & 2,8 & 2,8 & 2,8 \\
\hline & Precip (\%) & 5 & 5 & 5 & -10 & -10 & -10 & -10 & -10 & -10 & 5 & 5 & 5 \\
\hline \multirow{3}{*}{3} & Temp $\left({ }^{\circ} \mathrm{C}\right)$ & 2,8 & 2,8 & 2,8 & 2,8 & 2,8 & 2,8 & 2,8 & 2,8 & 2,8 & 2,8 & 2,8 & 2,8 \\
\hline & Precip (\%) & & & & & & & & & & & & \\
\hline & $\begin{array}{c}\text { Mais picos de } \\
\text { precip. }{ }^{*}\end{array}$ & -5 & -5 & -5 & -20 & -20 & -20 & -20 & -20 & -20 & -5 & -5 & -5 \\
\hline \multirow{3}{*}{4} & Temp $\left({ }^{\circ} \mathrm{C}\right)$ & 2,8 & 2,8 & 2,8 & 2,8 & 2,8 & 2,8 & 2,8 & 2,8 & 2,8 & 2,8 & 2,8 & 2,8 \\
\hline & Precip (\%) & & & & & & & & & & & & \\
\hline & $\begin{array}{c}\text { Mais picos de } \\
\text { precip. } *\end{array}$ & 5 & 5 & 5 & -10 & -10 & -10 & -10 & -10 & -10 & 5 & 5 & 5 \\
\hline
\end{tabular}

(*) Os cenários 3 e 4 foram construídos a partir dos cenários 1 e 2, respectivamente, mas adicionando-se o efeito da maior ocorrência dos picos de precipitação.

Essa situação foi criada pela inclusão de maiores valores históricos de total precipitado diário registrados na região nos dados de entrada referentes à precipitação, ano a ano. Isso quer dizer que, a base de dados climáticos do modelo foi alterada, de modo que existissem, no futuro, mais e maiores picos de precipitação em cada ano.

A partir desses cenários foi possível simular a ocorrência de: (i) períodos de seca mais intensa, representado pela diminuição do total precipitado no inverno (-20\%), principalmente nos cenários 1 e 3; (ii) períodos de chuva mais intensa no verão, como os evidenciados nos cenários 2 e 4, em que há um aumento de 5\% na precipitação de outubro a março; e (iii) aumento da frequência das precipitações mais intensas, conforme cenários 3 e 4, nos quais os volumes precipitados em alguns dias foram elevados, do que se pode inferir que haveria maior ocorrência de picos de precipitação. Como as variações na precipitação não ocorrem sozinhas, em todos os cenários há o aumento integrado da temperatura média diária em 2,8, que é a melhor estimativa para o aquecimento da Terra até 2099, conforme destacado na Tabela 2 para o cenário A1B, do IPCC (2007).

\section{RESULTADOS E DISCUSSÃO}

Como já foi dito, as mudanças no clima são consequência, principalmente, do aumento de $\mathrm{CO}_{2}$ na atmosfera. No SWAT foi possível simular mudanças na temperatura e precipitação na região de estudo, causadas por acréscimos assumidos da concentração de $\mathrm{CO}_{2}$.

Na Tabela 4 são apresentados os valores obtidos para as produções médias de sedimento e escoamento superficial para as simulações realizadas nos quatro cenários de alterações climáticas para o ano de 2099, anteriormente apresentados na Tabela 3, bem como o cenário atual para comparação, cujos valores foram obtidos a partir de Lelis (2011). 
Tabela 4. Produções médias de sedimento e escoamento superficial para diversos cenários de alterações climáticas da BHRSB, sendo os cenários de (1) a (4) referentes ao ano de 2099.

\begin{tabular}{c|c|ccccc}
\hline \multicolumn{2}{c|}{ Cobertura/Cenário } & Atual & (1) & (2) & (3) & (4) \\
\hline \multirow{2}{*}{ Pasto } & $\begin{array}{c}\text { Sedimento } \\
\text { (t/ha) } \\
\text { Esc. Superf. } \\
\text { (mm) }\end{array}$ & 0,288 & 0,257 & 0,333 & 0,554 & 0,616 \\
\hline \multirow{2}{*}{ Matá } & $\begin{array}{c}\text { Sedimento } \\
\text { (t/ha) } \\
\text { Esc. Superf. } \\
\text { (mm) }\end{array}$ & 0,007 & 0,006 & 0,008 & 0,011 & 0,013 \\
\hline $\begin{array}{c}\text { Sedimento } \\
\text { (t/ha) } \\
\text { Esc. Superf. } \\
\text { (mm) }\end{array}$ & 0,019 & 0,015 & 0,024 & 0,057 & 0,065 \\
\hline
\end{tabular}

Os resultados mostram que a bacia é extremamente sensível às alterações no clima. O Cenário 2099 (1) de redução de 5\% a 20\% no volume das precipitações apresenta quedas na produção de sedimentos e escoamento, como esperado, visto que a redução no total precipitado diário e aumento da evapotranspiração, em função do aumento da temperatura, ocasionam um maior déficit hídrico na região, diminuindo o total escoado e, consequentemente, pela diminuição da força de arraste das partículas, a produção de sedimentos. Já no cenário 2099 (2), há um aumento no volume precipitado no verão e redução no inverno. Dessa forma, há um leve acréscimo nas produções de sedimento e escoamento superficial durante o ano, mesmo com a redução da precipitação no inverno, nesse caso compensada pelo aumento da precipitação no verão, época em que os volumes precipitados são maiores.

Já nos cenários 2099 (3) e 2099 (4), que trazem o conceito de maior frequência dos picos de precipitação, há um grande aumento nas produções de sedimentos e escoamento superficial, indicando que o SWAT, mesmo não desenvolvido para simular eventos isolados de precipitação, interpreta bem a ocorrência desses picos durante o ano, promovendo a intensificação dos processos erosivos. $\mathrm{O}$ aumento das perdas registradas pode ser explicado pela alteração do tempo de concentração da bacia. Nos cenários simulados, o aumento da frequência dos eventos extremos de precipitação, mantendo as demais características da bacia constantes, promove a diminuição do tempo de concentração da bacia, provocando um aumento da vazão de pico e, consequentemente, maiores taxas de erosão.

Na Figura 5 apresentam-se os mapas da distribuição da produção de sedimentos e escoamento superficial para os cenários futuros simulados, bem como o cenário atual para comparação dos resultados obtidos, considerando que não haverá alteração na ocupação da bacia nos cenários apresentados. De acordo com os mapas apresentados, as áreas mais e menos críticas de perda de solo e escoamento superficial são coincidentes em todos os cenários, ratificando a interdependência desses fatores, independente da condição simulada. Em todos os cenários percebe-se, também, que a região norte da bacia, cuja ocupação é urbana (Lelis e Calijuri, 2010) é a principal responsável pela produção de sedimentos e escoamento superficial na região. As simulações realizadas podem servir como alerta, haja vista o grande volume de material transportado pelo fluxo superficial nos períodos de chuva que atingem a cidade de Viçosa, que obstrui e entope as vias pluviais, situação esta que tende a se agravar caso os cenários simulados, principalmente o cenário 4, venham a se concretizar. 
LELIS, T. A.; CALIJURI, M. L.; FONSECA, A. S. da; LIMA, D. C. de. Impactos causados pelas mudanças climáticas nos processos erosivos de uma bacia hidrográfica: Simulação de cenários. Ambi-Agua, Taubaté, v. 6, n. 2, p. 282-294, 2011. (doi:10.4136/ambi-agua.200)
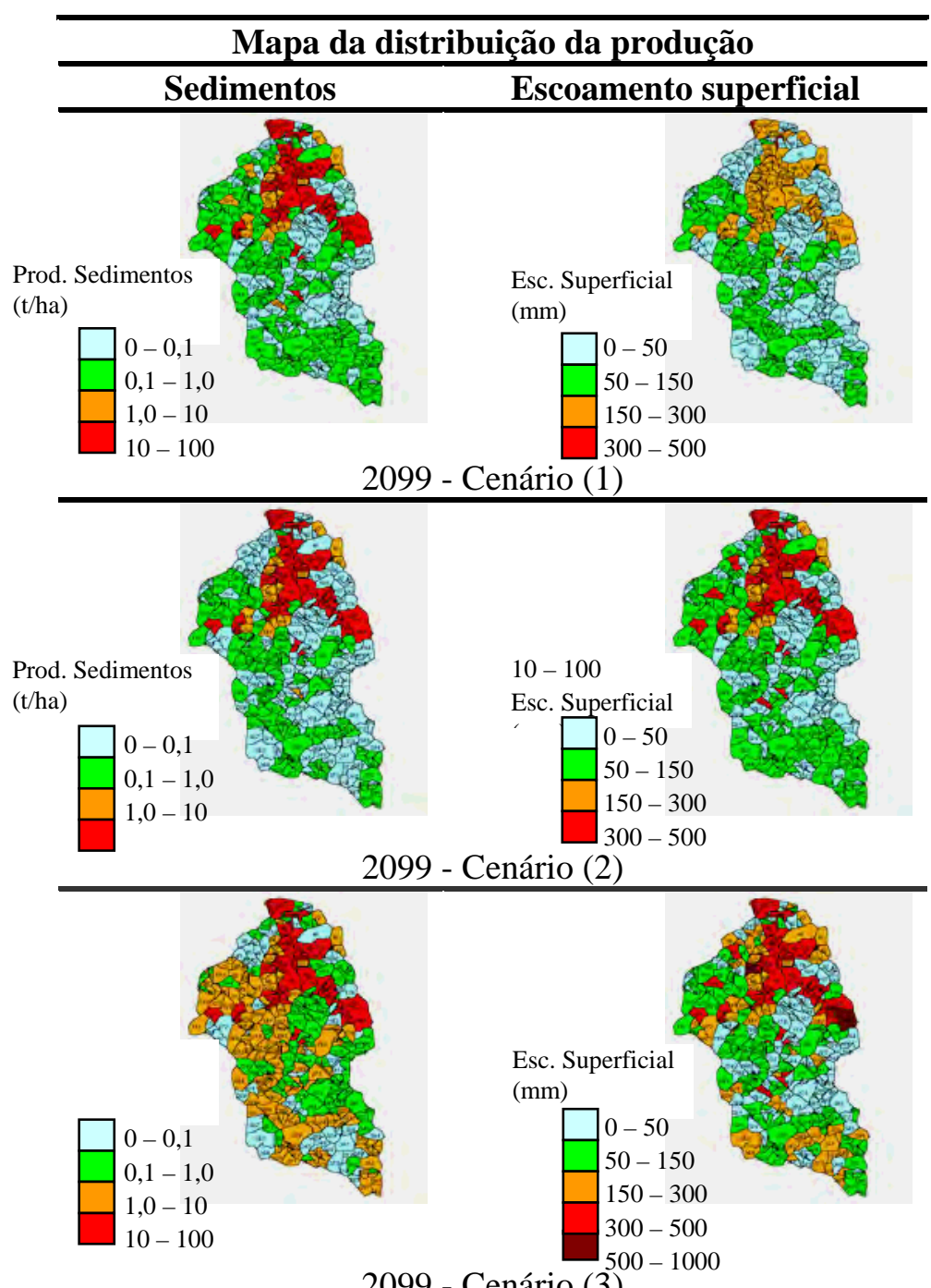

2099 - Cenário (3)
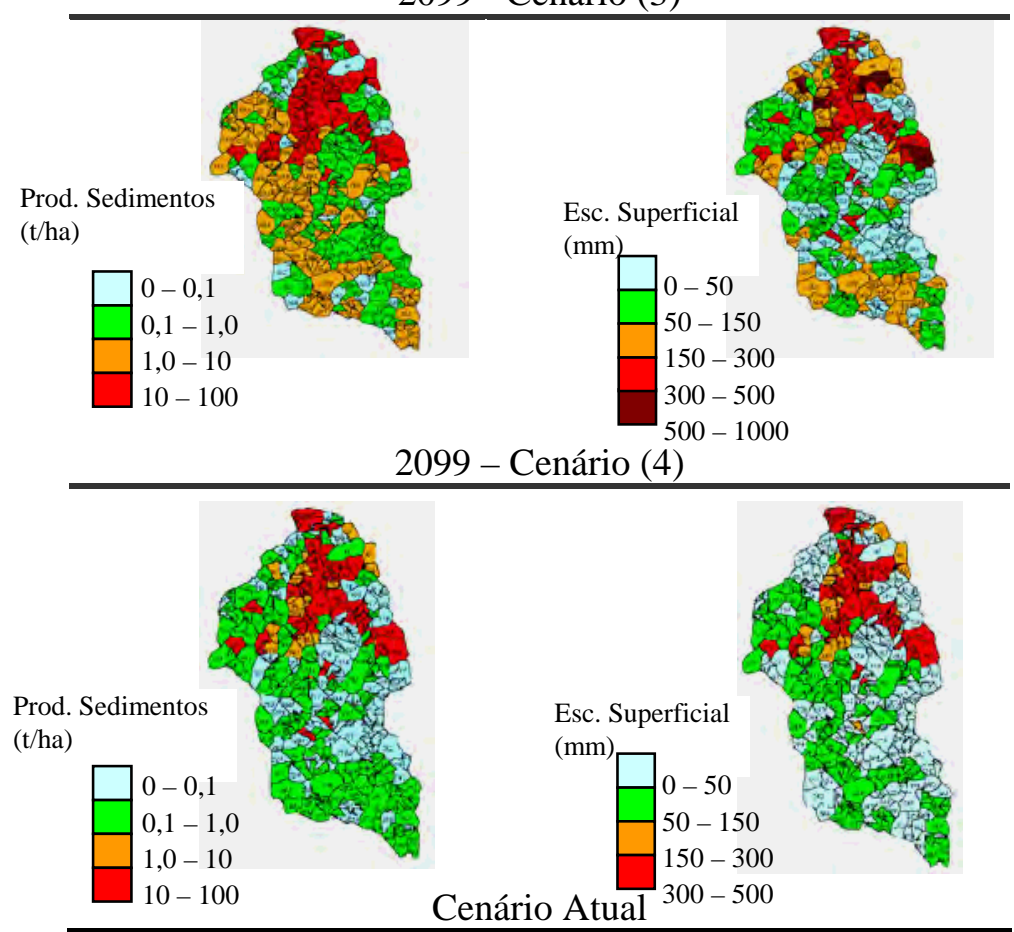

Figura 5. Mapa da distribuição da produção de sedimentos e escoamento superficial para a BRSB para diferentes cenários futuros de alteração climática e cenário atual. 
Pela Figura 5 percebe-se, também, que em todos os cenários simulados, a parte intermediária da bacia tende a ser menos susceptível à erosão, caso não haja alteração na sua ocupação, em razão da predominância de mata secundária (Lelis e Calijuri, 2010).

\section{CONCLUSÕES}

1. Os cenários simulados, segundo as previsões para mudança no clima do Painel Intergovernamental de Mudanças Climáticas, são bastante alarmantes, com taxas de produção de perda de solo e escoamento muito superiores às hoje encontradas, podendo chegar até a três vezes mais.

2. Mesmo genéricas, estas projeções atendem bem ao objetivo deste trabalho, que foi interpretar a variação da produção de sedimentos e escoamento superficial provocada por possíveis mudanças climáticas na bacia, validando a utilização do SWAT para esse tipo de estudo.

3. As simulações devem servir como subsídio para ações voltadas para o planejamento da bacia na definição de ações que possam conter o processo erosivo, pois refletem o cenário de acordo com as mudanças climáticas previstas para acontecerem nos próximos 90 anos.

\section{REFERÊNCIAS}

AMORE, E.; MODICA, C.; NEARING, M. A.; SANTORO, V. C. Scale effect in USLE and WEPP application for soil erosion computation from three Sicilian basins. Journal of Hydrology, v. 293, p. 100-114, 2004. http://dx.doi.org/10.1016/j.jhydrol.2004.01.018

AMORIM, R. S. S. Desprendimento e arraste de partículas de solo decorrentes de chuvas simuladas. 2000. 74f. Dissertação (Mestrado em Engenharia Agrícola) - Universidade Federal de Viçosa, Viçosa, MG, 2000.

AMORIM, R. S. S. Avaliação dos modelos de predição da erosão hídrica USLE, RUSLE e WEPP para condições edafoclimáticas brasileiras. 2004. 120f. Dissertação (Doutorado em Engenharia Agrícola) - Universidade Federal de Viçosa, Viçosa, MG, 2004.

BRANDÃO, V. S.; SILVA, D. D.; RUIZ, H. A.; PRUSKI, F. F.; SCHAEFER, C. E. G. R.; MARTINEZ, M. A. et al. Perdas de solo e caracterização física e micromorfológica de crostas formadas em solos sob chuva simulada. Eng. Agríc., Jaboticabal, v. 27, n. 1, p. 129-138, 2007.

CARVALHO, N. O. Hidrossedimentologia prática. 2. ed. Rio de Janeiro: Interciência, 2008. 602 p.

CLARKE, R. T. ; SILVA DIAS, P. L. As necessidades de observação e monitoramento dos ambientes brasileiros quanto aos recursos hídricos. Centro de Gestão e Estudos Estratégicos, Secretaria Técnica do Fundo Setorial de Recursos Hídricos. 2002. Disponível em : < http://www.finep.gov.br/fundos_setoriais/ct_hidro/documentos/cthidro01obs_e_monit_amb_rh.pdf $>$. Acesso 27 jul. 2011. 43 p.

EMPRESA BRASILEIRA DE PESQUISA AGROPECUÁRIA - EMPBRAPA. Atlas climatológico do Estado de Minas Gerais. Belo Horizonte, 1982. 60 p. 
GASSMAN, P. W.; REYES, M. R.; GREEN, C. H.; ARNOLD, J. G. The soil and water assessment tool: historical development, applications, and future research directions, Trans. ASAE, v. 50, n. 4, p. 1211-1250, 2007.

GOUVEA, J. R. F. Mudanças climáticas e a expectativa de seus impactos na cultura de cana-de-açúcar na região de Piracicaba, SP. 2008. 98f. Dissertação (Mestrado em Física do Meio Ambiente) - Escola Superior de Agricultura Luiz de Queiroz, Universidade de São Paulo, Piracicaba, 2008.

INTERGOVERNMENTAL PANEL ON CLIMATE CHANGE - IPCC. Novos cenários climáticos. 2007. Disponível em: <http://www.ecolatina.com.br/pdf/IPCC-COMPLETO. pdf>. Acesso 27 jul. 2011.

JHA, M.; ARNOLD, J. G.; GASSMAN, P. W.; GIORGI, F.; GU, R. Climate change sensitivity assessment on Upper Mississippi River Basin streamflows using SWAT. Journal of American Water Resources Association, v. 42, n. 4, p. 997-1016, 2006. http://dx.doi.org/10.1111/j.1752-1688.2006.tb04510.x

LELIS, T. A.; CALIJURI, M. L. Modelagem hidrossedimentológica de bacia hidrográfica na região sudeste do Brasil, utilizando o SWAT. Revista Ambiente \& Água, v. 5, n. 2, p. 158-174, 2010.

LELIS, T. A. Modelagem do escoamento superficial e perda de solo na bacia do ribeirão São Bartolomeu, Zona da Mata de Minas Gerais, utilizando o simulador SWAT. 2011. 164f. Dissertação (Doutorado em Engenharia Civil) - Universidade Federal de Viçosa, Viçosa, MG, 2011.

LOPES, N. H. Y. Análise da produção de água e sedimentos em microbacias experimentais com o modelo SWAT. 2008. 154f. Dissertação (Mestrado em Engenharia Ambiental) - Universidade Federal de Santa Catarina, Florianópolis, 2008.

MACHADO, R. L.; CARVALHO, D. F.; COSTA, J. R.; OLIVEIRA, D. H.; PINTO, M. F. Análise da erosividade das chuvas associada aos padrões de precipitação pluvial na região de Ribeirão das Lajes (RJ). Revista Brasileira de Ciência do Solo, v. 32, p. 2113-1223, 2008.

MARENGO, J. Vulnerabilidade, impactos e adaptação à mudança do clima no Semiárido do Brasil. Cachoeira Paulista: CPTEC/INPE, 2004. 16 p.

MERMUT, A. R.; LUK, S. H.; ROMKENS, M. J. M.; POESEN, J. W. A. Soil loss by splash and wash during rainfall from two loss soils. Geoderma, v. 75, n. 3, p. 203-214, 1997. http://dx.doi.org/10.1016/S0016-7061(96)00091-2

MOHAMMED, Y. Climate change impact assessment on soil water availability and crop yield in Anjeni Watershed Blue Nile Basin. 2009. 123f. Thesis (Master of Science in Meteorology) - Arba Minch University, Arba Minch, 2009.

NOVO, M. E.; FERREIRA, J. P. C. L. Alterações climáticas e seus impactos em recursos hídricos subterrâneos de zonas insulares: metodologias de vulnerabilidade às alterações climáticas. In: CONGRESSO SOBRE PLANEJAMENTO E GESTÃO DAS ZONAS COSTEIRAS DOS PAÍSES DE EXPRESSÃO PORTUGUESA, 4., 2007. Anais... Disponível em: < http://www.apea.pt/xFiles/scContentDeployer_pt/docs/Doc153.pdf>. Acesso 27 jul. 2011. 11p. 
NUNES, J. P.; PACHECO, N. R. Informação geográfica e modelação para a gestão de bacias hidrográficas - consequências das alterações climáticas para os processos hidrológicos e erosivos: potenciar a informação geográfica para a gestão ambiental. In: ENCONTRO DE UTILIZADORES DE INFORMAÇÃO GEOGRÁFICA, 8., 2004. Anais... Oeiras. Disponível em: < http://www.igeo.pt/servicos/DPCA/biblioteca/publicacoesIGP/ESIG_ 2004/fichpdf.asp?file=p058.pdf $>$.Acesso: 27 jul 2011. 13 p.

REUNGSANG, P.; KANWAR, R. S.; JHA, M.; GASSMAN, P. W.; AHMAD, K.; SALEH, A. Calibration and validation of SWAT for the upper Maquoketa River Watershed. International Journal of Agricultural Engineering, v. 16, n. 1/2, p. 35-48, 2009.

SANTOS, G. G.; GRIEBELER, N. P.; OLIVEIRA, L. F. C. Chuvas intensas relacionadas à erosão hídrica. Rev. bras. Eng. Agríc. Ambient., Campina Grande, v. 14, n. 2, p. 115 123, 2010.

STRECK, N. A.; ALBERTO, C. M. Simulação do impacto da mudança climática sobre a água disponível do solo em agroecossistemas de trigo, soja e milho em Santa Maria, RS. Ciência Rural, Santa Maria, v. 36, n. 2, p. 424-433, 2006.

UNITED NATIONS FRAMEWORK CONVENTION ON CLIMATE CHANGE - UNFCCC. Convenção Quadro da ONU sobre mudança do clima. Nova Iorque, 1992.

XAVIER, F. V. Contribuição metodológica ao estudo da produção e distribuição espacial de sedimentos na bacia hidrográfica do Rio Manso, utilizando o modelo AVSWAT. 2009. 166f. Dissertação (Mestrado em Física Ambiental) - Universidade Federal do Mato Grosso, Cuiabá, 2009. 